\title{
Superficial Palmar Arch
}

National Cancer Institute

\section{Source}

National Cancer Institute. Superficial Palmar Arch. NCI Thesaurus. Code C33665.

An arterial anastomosis in the palm of the hand, located distal to the deep palmar arch, and fed mainly by the ulnar artery, providing the principal blood supply to the common and proper digital arteries. 